\title{
Herbal Medicine for Cough: a Systematic Review and Meta-Analysis
}

\author{
Luise Wagner ${ }^{a}$ Holger Cramer $^{b}$ Petra Klose $^{b}$ Romy Lauche ${ }^{b}$ Florian Gass $^{b}$ \\ Gustav Dobos $^{b}$ Jost Langhorst ${ }^{a, b}$
}

a Department of Integrative Gastroenterology, Kliniken Essen-Mitte, Essen, Germany;

${ }^{b}$ Department of Internal and Integrative Medicine, Kliniken Essen-Mitte,

Faculty of Medicine, University of Duisburg-Essen, Essen, Germany

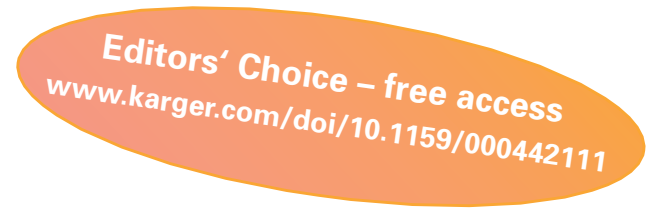

\section{Keywords}

Herbal medicine - Complementary therapies · Cough . Review · Meta-Analysis

\section{Summary}

Background: The aim of this review was to systematically assess the literature on herbal medicine for cough as a symptom of upper respiratory tract infections and common cold. Methods: The Cochrane Library, Scopus, MEDLINE/PubMed, and Embase were searched through March 2012 for RCTs testing the effects of herbal medicine for cough. Risk of bias was assessed using the Cochrane tool. Results: 34 RCTs ( $N=7,083$ ) on Pelargonium sidoides (11 RCTs), Echinacea (8 RCTs), Andrographis paniculata (6 RCTs), ivy/primrose/thyme (4 RCTs), essential oils (4 RCTs) and bakumondoto (1 RCT) were included. Controls were mainly placebo. Most studies had a low risk of bias. The meta-analysis revealed strong evidence for $A$. paniculata (SMD $=-1.00,95 \% \mathrm{Cl}=-1.85$, $-0.15 ; \mathrm{P}<0.001)$ and ivy/primrose/thyme $(R R=1.40,95 \%$ $\mathrm{Cl}=1.23,1.60 ; \mathrm{P}<0.001)$ in treating cough; moderate evidence for $P$. sidiodes $(\mathrm{RR}=4.60 ; 95 \% \mathrm{Cl}=2.89,7.31$; $\mathrm{P}<0.001$ ), and limited evidence for Echinacea (SMD = $-0.68 ; 95 \% \mathrm{Cl}=-1.32,-0.04 ; \mathrm{P}=0.04)$. Conclusion: This review found strong evidence for $A$. paniculata and ivy/ primrose/thyme-based preparations and moderate evidence for $P$. sidoides being significantly superior to placebo in alleviating the frequency and severity of patients' cough symptoms. Additional research, including other herbal treatments, is needed in this area.

(c) 2015 S. Karger GmbH, Freiburg

\section{Schlüsselwörter}

Phytotherapie · Komplementärmedizin · Husten ·

Übersichtsarbeit · Metaanalyse

\section{Zusammenfassung}

Hintergrund: Ziel dieser Übersichtsarbeit war die systematische Erfassung der Literatur zu Phytotherapie bei Husten als Symptom von Infektionen der oberen Atemwege. Methoden: Cochrane Library, Scopus, MEDLINE/ PubMed und Embase wurden bis einschließlich März 2012 nach RCTs zu Wirkungen von Phytotherapie bei Husten durchsucht. Das Risiko für Bias wurde nach den Maßgaben der Cochrane Collaboration über das Cochrane-Tool erfasst. Ergebnisse: 34 Studien ( $N=7083$ ) zu Pelargonium sidoides (11 Studien), Echinacea (8 Studien), Andrographis paniculata (6 Studien), Efeu/Primel/ Thymian (4 Studien), ätherischen Ölen (4 Studien) und Bakumondoto (1 Studie) wurden eingeschlossen. Placebo war die häufigste Kontrollintervention. Die meisten Studien hatten ein geringes Risiko für Bias. Die Metaanalye ergab starke Evidenz für $A$. paniculata (SMD $=-1,00$, $95 \% \mathrm{KI}=-1,85 ;-0,15 ; \mathrm{P}<0,001)$ und Efeu/Primel/ThymianPräparate $(R R=1,40,95 \% K I=1,23 ; 1,60 ; P<0,001)$, moderate Evidenz für $P$. sidiodes ( $R R=4,60 ; 95 \% \mathrm{KI}=2,89$; $7,31 ; P<0,001)$ und eingeschränkte Evidenz für Echinacea (SMD $=-0,68 ; 95 \% \mathrm{KI}=-1,32 ;-0,04 ; \mathrm{P}=0,04)$. Schlussfolgerung: Diese Übersichtsarbeit ergab starke Evidenz für Effekte von $A$. paniculata und Efeu/Primel/Thymian-Präparaten sowie moderate Evidenz für Effekte von $P$. sidoides auf die Frequenz und Schwere von Hustensymptomen, mit einem signifikanten Unterschied gegenüber Placebo. $\mathrm{Zu}$ anderen Phytotherapeutika ist weitere Forschung notwendig. 


\section{Background}

Cough is a common, persistent symptom of many acute and chronic diseases. Its disruptive effects drive many patients to consult their doctors and underpin a multi-million dollar industry in over-the-counter remedies [1]. Acute cough symptoms commonly result from infection (upper respiratory tract infection (URTI) or common cold) or environmental exposure to smoke and/or allergens. Whilst most people experience a cough at least once in their lives, its frequency is linked to factors such as gender and allergen sensitivity $[2,3]$. There is no evidence that any classic mucolytic, including $\mathrm{N}$-acetyl cysteine (NAC), eases patients' symptoms by helping them to expectorate mucus [4]. Trials of over-the-counter remedies, such as cough syrups and cough suppressants, have also failed to produce consistent, objective benefits [5]. Herbal medicines are part of a wide range of treatments such as phytotherapies, hydrotherapies, and Traditional Chinese Medicine (TCM), few of which are applied in conventional medicine. Whilst herbal treatments have a long history of use in varied cultures, randomized controlled trial (RCT) data on their effects is generally lacking [68]. Herbal cough treatments with proven clinical efficacy include ivy/primrose/thyme-based preparations which are recommended as expectorants in current European guidelines [9]. This review and meta-analysis was conducted to summarize and evaluate existing high-quality data on the use of herbal medicines in the treatment of cough in adults and children.

\section{Methods}

\section{Literature Search}

The literature on phytotherapeutic treatments for cough was searched in March 2012, via the Cochrane Library, MEDLINE (PubMed), Scopus, and Embase databases. Initially, 'cough' was searched as a generic symptom, not related to specific medical conditions or etiologies, treated with different complementary and alternative medicine (CAM) approaches. The treatments were chosen according to the definitions provided by the National Institutes of Health's National Center for Complementary and Alternative Medicine (NIH/NCCAM, www.nccam.nih.gov). Other search terms focused on 'cough' as a symptom of varied respiratory conditions including: 'bronchitis', 'common cold', 'respiratory tract infection', 'upper respiratory tract infection', 'lower respiratory tract infection', 'pneumonia', 'chronic pulmonary diseases', 'chronic obstructive pulmonary disease', 'pulmonary disease', 'respiratory dysfunction', 'flu', and 'influenza'. These terms were then combined with different phytotherapeutic agents.

\section{Eligibility Criteria}

To be eligible for review, studies had to meet the following criteria:

(1) Types of studies: RCTs were eligible, but only if published as full research articles.

(2) Types of participants: Only studies conducted in humans were included. Participants were required to have experienced cough as a symptom of URTI or common cold, in the absence of other chronic disease. There were no limitations on age.

(3) Types of interventions: Studies were required to have compared a phytotherapeutic agent to either a placebo, to no intervention, or to other agents. Studies where phytotherapeutics were not the main intervention were excluded. No limitations were imposed concerning the duration of the application, dosage, or the form of the herbal medication used.

(4) Language: Only studies published in English or German were included.

\section{Selection of Studies}

Two review authors independently screened abstracts identified during the literature search, reading potentially eligible articles in full to determine the extent to which they met the eligibility criteria. Disagreements were discussed with a third reviewer until consensus was reached.

\section{Risk of Bias in Individual Studies}

The two independent reviewers assessed studies' risk of bias, analyzing potential selection bias, performance bias, attrition bias, reporting bias, and detection bias as recommended in guidelines published by the Cochrane Back Review Group [10]. These guidelines specify 12 questions to be answered with 'yes', 'no', or 'unclear' in order to judge studies' quality. The latter judgment was made when the articles included insufficient information and when additional study details were not provided when inquired. Studies that scored 6 points or more were categorized as having a low risk of bias. Those that scored less than 6 points or included a serious flaw were assessed as having a high risk of bias. Any disagreements in the assessments made were resolved via discussion with the other authors of the review. The details and results of the evaluated studies are shown in appendices I and II (www.karger.com/doi/10.1159/000442111).

\section{Assessment of Overall Effect Size}

Overall effect sizes were estimated, if at least 2 trials assessed the same specific outcome, using 'Review Manager 5' software (Version 5.1, The Nordic Cochrane Centre, Copenhagen, Denmark). Concerning continuous outcomes, standardized mean differences (SMD) with 95\% confidence intervals (CI) were calculated as the difference in means between the studied groups divided by the pooled standard deviation (SD). In studies where SD was not reported, it was calculated from standard errors, CIs, or t-values. In other cases, missing data was acquired from the original study author. Cohen categories were applied to assess the dimension of the overall effect size with: (a) SMD $=0.2-0.5$ (small); (b) $\mathrm{SMD}=0.5-0.8$ (moderate); and (c) SMD $=>0.8$ (large) [11]. For dichotomous outcomes, risk ratios (RR) with $95 \% \mathrm{CI}$ were generated by dividing the risk of the event occurring in the experimental group (i.e. the number of participants with the respective outcome divided by the total number of participants) by the risk of the event occurring in the control group. Different levels of evidence were defined as follows, according to the Cochrane Back Review Group's recommendations: (a) strong evidence: consistent findings among multiple RCTs with a low risk of bias; (b) moderate evidence: consistent findings among multiple high-risk RCTs and/or one low-risk RCT; (c) limited evidence: one RCT with a high risk of bias; (d) conflicting evidence: inconsistent findings among multiple RCTs; (e) no evidence: no RCTs [12].

\section{Assessment of Heterogeneity}

To quantify the statistical heterogeneity between the reviewed studies, $\mathrm{I}^{2}$ statistics were used. Different $\mathrm{I}^{2}$ values indicate varying heterogeneity: $\mathrm{I}^{2}>30 \%=$ moderate; $\mathrm{I}^{2}>50 \%=$ substantial; $\mathrm{I}^{2}>75 \%=$ considerable [13]. To assess whether differences in the study results could result solely from chance, $\chi^{2}$-test was used. Significant heterogeneity was suggested by a P-value of $\leq 0.10$ [13].

\section{Risk of Bias across Studies}

Publication bias was assessed by a visual analysis of forest plots generated by using the 'Review Manager 5' software if at least 2 studies were included in a meta-analysis. Asymmetric funnel plots suggest a high risk of study bias; symmetric ones suggest a low risk of bias [13].

\section{Results}

The literature search yielded 887 articles, 252 of which were excluded as duplicates. Of the remaining 635 studies, a further 499 were excluded after abstract screening. Further 102 studies were excluded, usually due to the complexity of participants' pathologies or due to the fact that the interventions were not phytotherapeutic 
(appendix III; www.karger.com/doi/10.1159/000442111). In the end, 34 studies remained for the qualitative review and 16 studies were included in the meta-analysis (fig. 1).

In the remaining $34 \mathrm{RCTs}$, the use of following remedies against cough was assessed: A. paniculata $(\mathrm{n}=6)$, essential oils $(\mathrm{n}=4)$, Echinacea $(\mathrm{n}=8)$, ivy/primrose/thyme $(\mathrm{n}=4), P$. sidoides $(\mathrm{n}=11)$, and bakumondoto (a TCM phytotherapeutic agent) $(n=1)$.

\section{Study Characteristics}

A total of 7,083 individuals participated in the analyzed studies, with an average of 226 participants (range 20-640) in 2-3 interven-

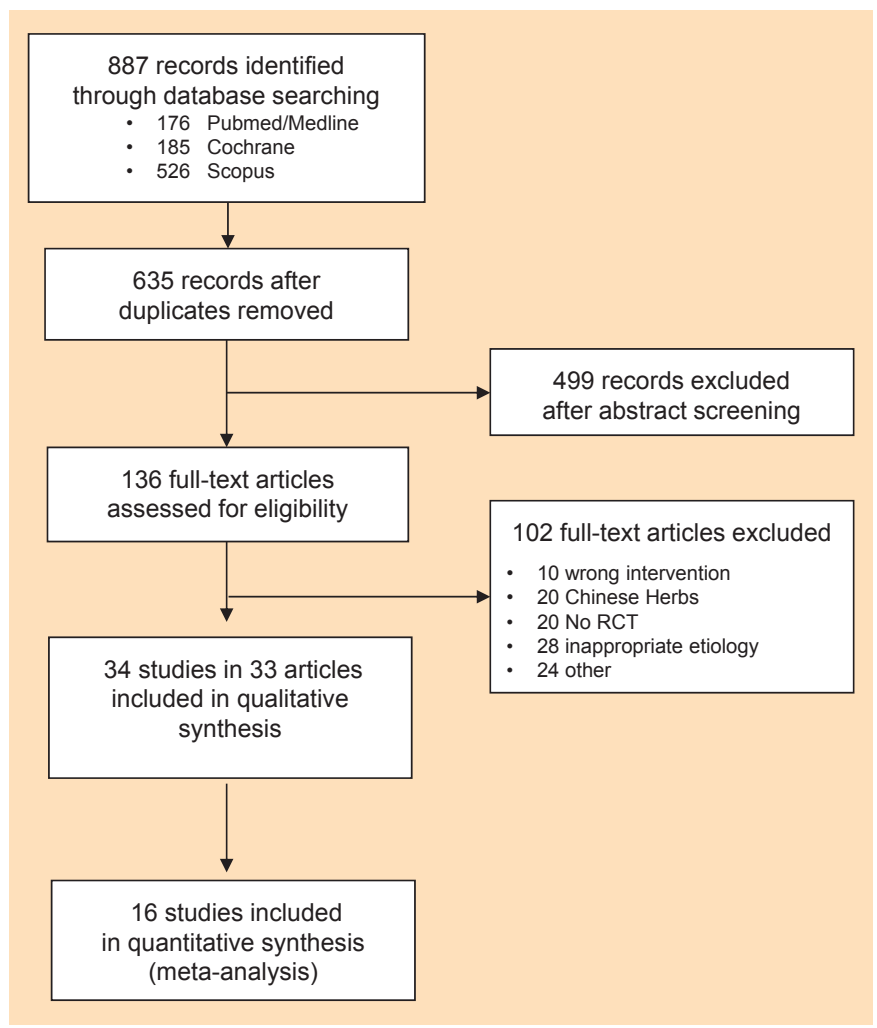

Fig. 1. Flowchart of literature search results. tion groups per intervention. Patients ranged from 1-86 years in age; with most studies including adults only. 6 trials included children as test population. Details of the analyzed studies, including the characteristics of the study samples, the interventions used, the outcome assessments performed, and the results obtained are shown in appendix I (www.karger.com/doi/10.1159/000442111).

\section{Outcome Measures}

Most studies used subjective evaluation methods to assess the clinical efficacy of the administered herbal cough remedies. These methods included symptom diaries, total daily symptom scores (TDSS), and symptom-related questionnaires completed by patients. Common assessment instruments, such as visual analogue and verbal rating scales, were also used to facilitate comparison of the resulting study data. Data on changes in patients' symptoms were equally subjective.

\section{Risk of Bias in Individual Studies}

Most RCTs were evaluated as being of good quality, with a low risk of performance, attrition, or reporting bias. Only 4 studies [14-17] were seen as having a high risk of bias, due to missing information. Study randomization and allocation concealment processes were generally unclear throughout these studies.

\section{Analyses of Overall Effects}

These effects are illustrated in fig. 2-7 and detailed below.

\section{Effects of Individual Phytotherapeutic Agents}

\section{Andrographis paniculata}

Six RCTs, with a total of 807 participants, were located [18-22]. Five of these studies tested a special preparation of $A$. paniculata versus placebo [18-20, 22]. The remaining study used Echinacea in another intervention group [21] and bromhexine as control intervention in treating common cold and URTI. Three different preparations were used for the active treatment groups: KalmCold ${ }^{\circledR}$ cap-
Fig. 2. Effects of $A$. peniculata on frequency of cough. $\mathrm{CI}=$ confidence interval; $\mathrm{IV}=$ inverse variance; $\mathrm{SD}=$ standard deviation.

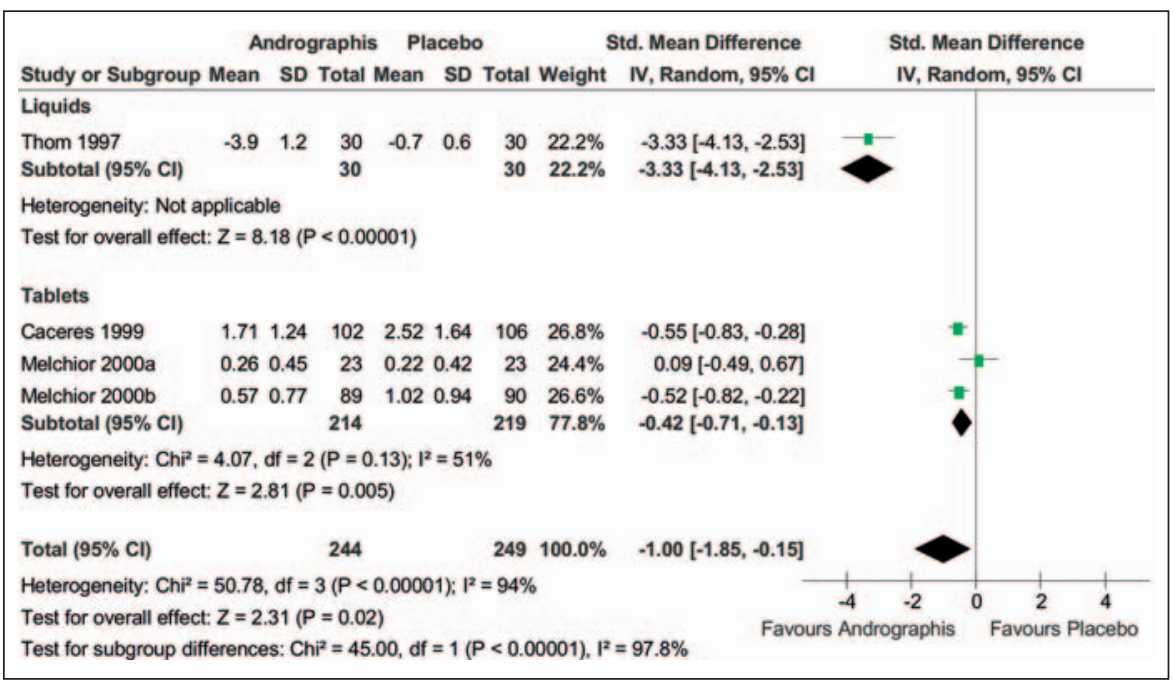


Fig. 3. Effects of A. peniculata on severity of cough. $\mathrm{CI}=$ confidence interval; $\mathrm{IV}=$ inverse variance; $\mathrm{SD}=$ standard deviation.

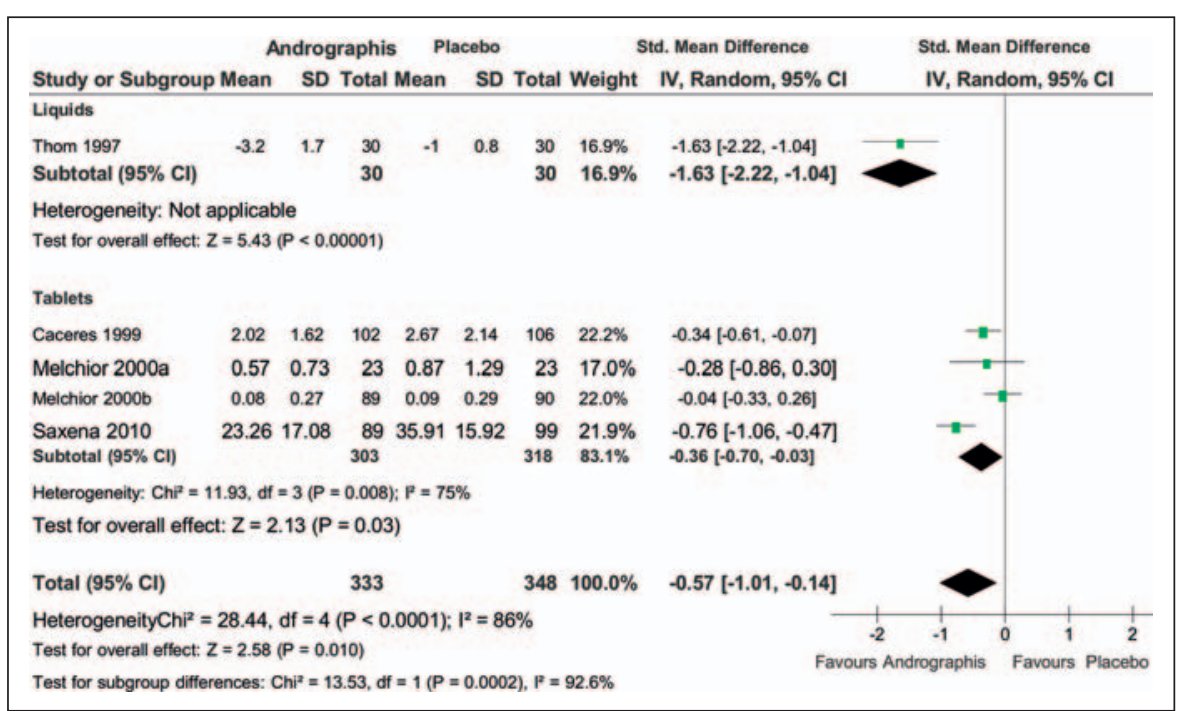

sules, KanJang ${ }^{\circledR}$ tablets, and KanJang ${ }^{\circledR}$ oral solution. KanJang ${ }^{\circledR}$ preparations combine extracts of $A$. paniculata and Echinacea. The daily doses taken ranged from $31.5 \mathrm{mg}$ to $200 \mathrm{mg}$; the duration of intake was 3-10 days.

Most studies showed significant improvements in active treatment group patients with cough-related symptoms. The study by Narimanian et al. [21] showed particularly good results for mucociliary clearance. The sole exception was the trial conducted by Melchior et al. [20]; a pilot study with relatively few patients. All studies reported small numbers of mild adverse effects, including nausea, emesis, vertigo, skin rash and diarrhea, but none required further treatment.

Four trials [18-20,22] were assessed quantitatively with regard to changes in the frequency of patients' cough symptoms. In these studies, meta-analysis showed strong evidence that $A$. paniculata reduced this frequency $(\mathrm{SMD}=-1.00,95 \% \mathrm{CI},-1.85$ to -0.15 ; $\mathrm{P}=0.02)$, although significant heterogeneity was found in the original study results $\left(\mathrm{I}^{2}=94 \%, \chi^{2}=50.78 ; \mathrm{P}<0.00001\right.$; fig. 2$)$. These 5 trials were also compared with regard to changes in the severity of patients' cough symptoms $[18-20,22]$. The results showed strong evidence for the benefit of phytotherapeutics in this area, although significant heterogeneity was found here, too $(\mathrm{SMD}=-0.57$, $95 \% \mathrm{CI},-0.70$ to $-0.03 ; \mathrm{P}=0.03$; heterogeneity: $\mathrm{I}^{2}=86 \% ; \chi^{2}=28.44$; $\mathrm{P}<0.0001$; fig. 3). These analyses show that $A$. paniculata is effective in reducing the frequency and severity of patients' cough symptoms.

The quality of the analyzed studies was good; scoring 7-10 on the Cochrane Back Review Group scale [10]. Only Narimanian et al. [21] and Thom [22] failed to describe their randomization strategy in adequate detail.

\section{Pelargonium sidoides}

Eleven studies exploring the effects of $P$. sidoides in treating acute upper respiratory tract infections were found [17, 23-32]. 2,871 patients participated in these studies; an average of 261 in each. Seven studies were conducted solely with adults. The remaining 4 studies were conducted with children and adolescents aged 1-18 years [2932]. The regimen dosages varied according to participants' ages.

Most studies included more than one intervention group with varied intervention dosages $(90 \mathrm{mg}$ to $7,2 \mathrm{~g}$ in adults and $30 \mathrm{mg}$ to $3,6 \mathrm{~g}$ in children). In most studies, a total dose of $3.6 \mathrm{~g}$ per day was used $[24,25,27,28,30]$. Oral preparations of $P$. sidoides (EPs $7,630)$ were generally used. Most studies explored the effects of CAM on URTI, evaluating the severity of symptoms using the Bronchitis Severity Score (BSS) consisting of 5 symptom items including cough. The study outcomes assessed patients' quality of life and satisfaction with the intervention medications by using questionnaires, such as the EuroQol Visual Analogue Scale (EQVAS), EuroQol 5D (EQ-5D), Integrative Medicine Outcome Scale (IMOS), and Integrative Medicine Patient Satisfaction Scale (IMPSS).

All studies, except one, [32] found that patients with URTI benefitted from $P$. sidoides, especially with regard to their cough symptoms. In the active treatment groups, the BSS improved significantly as well as other URTI-related symptoms (e.g. fever, sore throat, fatigue). Patients also reported satisfaction with their quality of life and the process of alleviating their complaints. Only the study by Blochin and Haidvogl [32] showed no significant changes in patients' BSS. Matthys et al. [23] also noted improvements in patients' general well-being with $P$. sidoides, even though their symptom scores were not significantly reduced. In most studies, mild adverse effects could be achieved. For example, Kamin [30] found that $28 \%$ of the children included in the study experienced such effects although these effects were distributed equally between the active treatment and the placebo groups.

The results of the $P$. sidoides studies were analyzed for adults and children separately (fig 4,5 ). Five study groups were analyzed for adults $[17,23,26,27]$. These results showed moderate evidence for benefit from the application of $P$. sidoides, compared to controls $(\mathrm{RR}=4.60 ; 95 \% \mathrm{CI}, 2.89$ to $7.31 ; \mathrm{P}=0.00001)$, with moderate heterogeneity in these results $\left(\mathrm{I}^{2}=0 \% ; \chi^{2}=0.46 ; \mathrm{P}=0.98\right)$. In children, the use of $P$. sidoides was also proved beneficial, compared to 
Fig. 4. Effects of $P$. sidoides on cough in adults. $\mathrm{CI}=$ confidence interval; $\mathrm{IV}=$ inverse variance .

Fig. 5. Effects of $P$. sidoides on cough in children. $\mathrm{CI}=$ confidence interval; $\mathrm{IV}=$ inverse variance

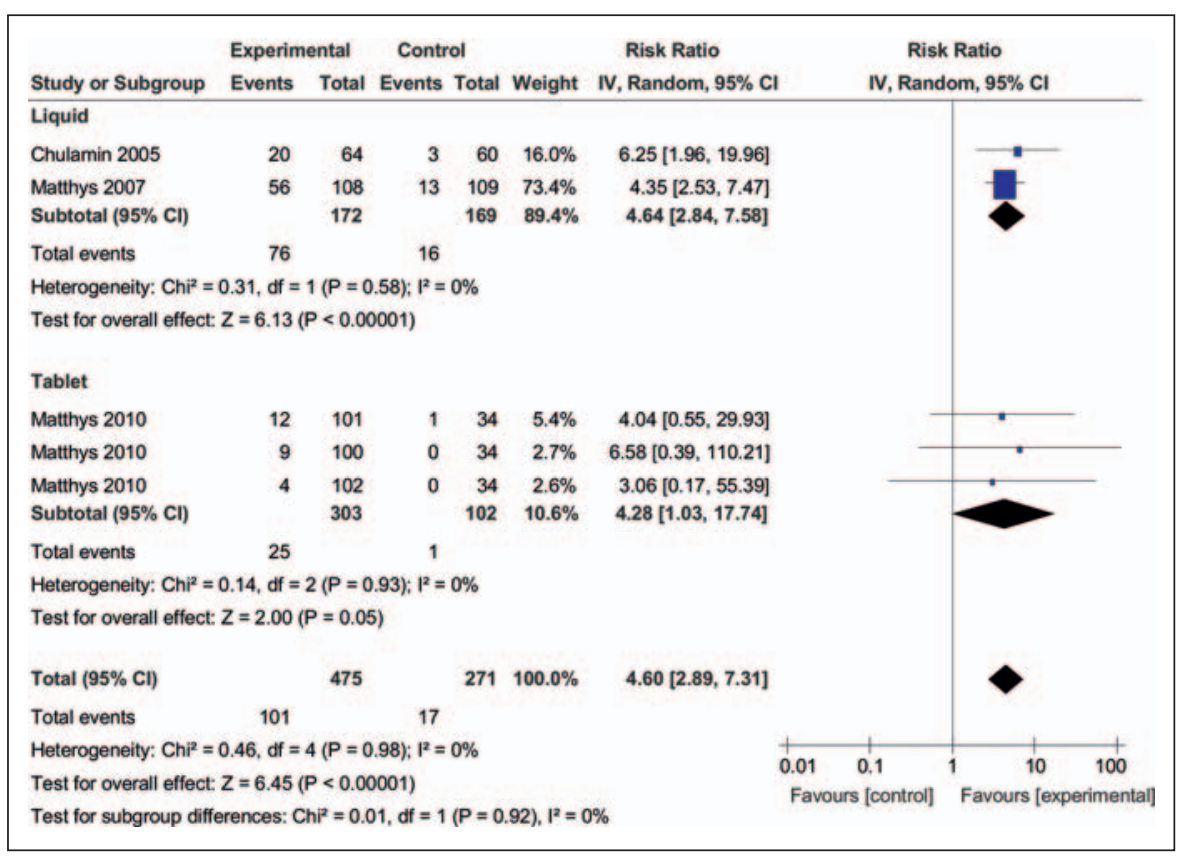

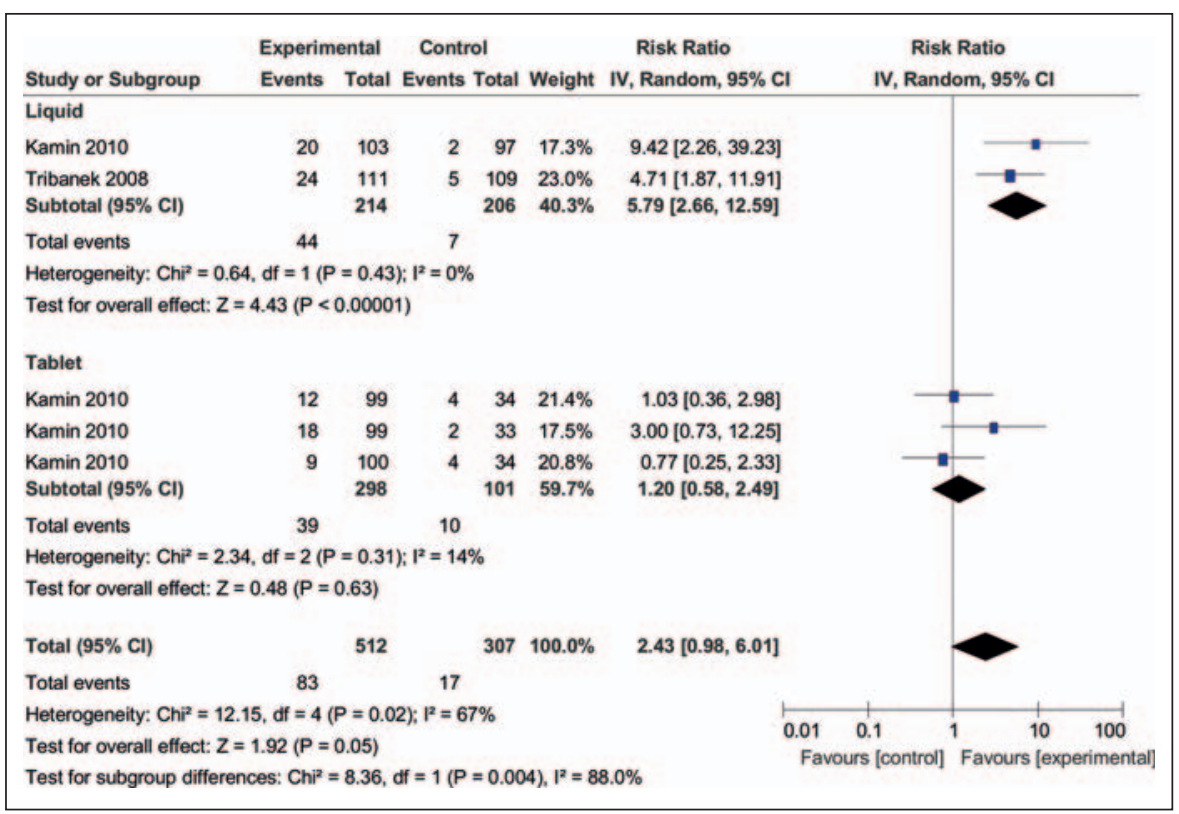

controls (5 study groups were analyzed [30, 31, 33], although the respective CI ranges indicated that the power of positive effects found in the active treatment group was equivocal $(\mathrm{RR}=2.43 ; 95 \%$ CI, 0.98-6.01; $\mathrm{P}=0.05)$. Substantial heterogeneity was also found in these results $\left(\mathrm{I}^{2}=67 \% ; \chi^{2}=12.15 ; \mathrm{P}=0.02\right)$.

Except for the study by Matthys [23], all of the P. sidoides studies were of very good quality, with a low risk of bias.

\section{Ivy, Primrose, and Thyme}

Four RCTs were identified in which an ivy/primrose/thymebased preparation was used to treat patients' cough symptoms [3437]. These studies included a total of 1,428 patients with an average of 357 participants in each study.
One study compared the effects of a combination of 2 herbal medications, but had no placebo-based control group [36]. The remaining studies compared active agents with a placebo. Most participants were adults; in one study [36] both children (older than 2 years) and adults were included.

Most of these studies used well-known, proprietary herbal medications, such as Bronchipret ${ }^{\circledR}$ (tablets and oral solution), Hedelix ${ }^{\circledR}$, Prospan ${ }^{\circledR}$ (oral solutions), and Mintetten ${ }^{\circledR}$; supplied by their manufacturers.

All studies reported excellent results from the different CAM interventions. Cwientzek [36] rated the efficacy of both phytotherapeutic medications as equally good, with no difference between the study groups. Kurth [37] noted that these preparations not only 


\begin{tabular}{|c|c|c|c|c|c|c|c|c|}
\hline \multirow{2}{*}{$\begin{array}{l}\text { Study or Subgroup } \\
\text { Liquids }\end{array}$} & \multicolumn{2}{|c|}{ Verum } & \multicolumn{2}{|c|}{ Placebo } & \multirow[t]{2}{*}{ Weight } & \multirow[t]{2}{*}{$\begin{array}{l}\text { Risk Ratio } \\
\text { IV, Random, } 95 \% \mathrm{CI}\end{array}$} & \multicolumn{2}{|c|}{$\begin{array}{c}\text { Risk Ratio } \\
\text { IV, Random, } 95 \% \mathrm{CI}\end{array}$} \\
\hline & & & & & & & & \\
\hline Kemmerich 2006 & 151 & 182 & 96 & 178 & $45.6 \%$ & $1.54[1.32,1.79]$ & & \\
\hline Subtotal $(95 \% \mathrm{Cl})$ & & 182 & & 178 & $45.6 \%$ & $1.54[1.32,1.79]$ & & \\
\hline Total events & 151 & & 96 & & & & & \\
\hline \multicolumn{9}{|c|}{ Heterogeneity: Not applicable } \\
\hline \multicolumn{9}{|c|}{ Test for overall effect: $Z=5.59(P<0.00001)$} \\
\hline \multicolumn{9}{|l|}{ Tablets } \\
\hline Kemmerich 2007 & 141 & 182 & 107 & 178 & $48.5 \%$ & $1.29[1.12,1.49]$ & & \\
\hline Kurth 1978 & 19 & 38 & 14 & 39 & $5.9 \%$ & $1.39[0.82,2.36]$ & & \\
\hline Subtotal $(95 \% \mathrm{Cl})$ & & 220 & & 217 & $54.4 \%$ & $1.30[1.13,1.49]$ & & \\
\hline Total events & 160 & & 121 & & & & & \\
\hline \multicolumn{9}{|c|}{ Heterogeneity: $\mathrm{Chi}^{2}=0.08, \mathrm{df}=1(\mathrm{P}=0.78) ; \mathrm{l}^{2}=0 \%$} \\
\hline \multicolumn{9}{|c|}{ Test for overall effect: $Z=3.68(P=0.0002)$} \\
\hline Total $(95 \% \mathrm{Cl})$ & & 402 & & 395 & $100.0 \%$ & $1.40[1.23,1.60]$ & & \\
\hline Total events & 311 & & 217 & & & & & \\
\hline \multirow{3}{*}{\multicolumn{9}{|c|}{ Test for overall effect: $Z=5.05(P<0.00001)$}} \\
\hline & & & & & & & & \\
\hline Test for subgroup diff & ferences: & $\mathrm{Chi}^{2}=$ & $2.71, \mathrm{df}$ & $=1(P$ & $=0.10), 1$ & $I^{2}=63.1 \%$ & & \\
\hline
\end{tabular}

Fig. 6. Effects of ivy/primrose/thyme on cough. $\mathrm{CI}=$ confidence interval; $\mathrm{IV}=$ inverse variance . though the study by Matthys et al. [38] and Paul et al. [39] lacked sufficient information about the appropriateness of their randomization and blinding processes; Gillissen et al. [40] did not report mean or standard deviations. In the remaining study [14], necessary data was missing, leading to a high risk of potential bias.

\section{Echinacea}

We found 8 studies exploring the use of a varied range of solid and liquid Echinacea preparations in the treatment of cough symptoms for common cold or URTI [16, 41-47]. A total of 1,130 patients were enrolled in these studies, with an average of $141 \mathrm{pa}-$ tients per study. Seven studies were conducted with adults and one with children aged 1-12 years [42]. The dosage of Echinacea differed markedly between the studies, from $300 \mathrm{mg}$ to $6 \mathrm{~g}$ daily. The duration of intake ranged from one to 12 weeks.

Most studies did not report any significant reduction in patients' cough symptoms. Only Cohen et al. [42] found a significant improvement in nighttime cough. Daytime cough symptoms also improved in this study, but this change did not reach statistical significance. Although Echinacea was not found to influence patients' cough symptoms, it did diminish their other common cold symptoms [16, 42, 43, 45]. In 2 of these studies [42, 45] Echinacea reduced the duration of patients' symptoms. Patients reported only a few mild, mainly gastrointestinal adverse effects. These were selflimiting and needed no further treatment.

Two of these studies $[16,45]$, assessing the overall effect size, showed limited evidence for Echinacea's benefits, compared to controls (SMD $=-0.68 ; 95 \% \mathrm{CI},-1.32$ to $-0.04 ; \mathrm{P}=0.04$ ), with significant heterogeneity in the results $\left(\mathrm{I}^{2}=79 \% ; \chi^{2}=4.78 ; \mathrm{P}=0.03\right)$ (fig. 7). The quality of the reviewed studies was generally good, with only one single study [16] containing insufficient details and thus leading to a potentially high risk of bias.
A meta-analysis could not be conducted in this area, missing data. The quality of the 3 studies [38-40] was good, al- 
Fig. 7. Effects of Echinacea on cough. $\mathrm{CI}=$ confidence interval; IV = inverse variance.

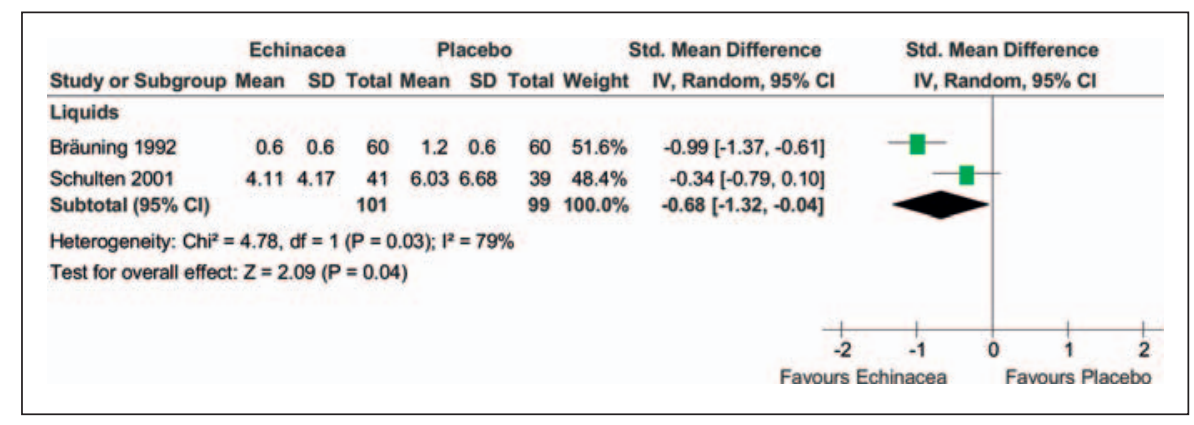

\section{Bakumondoto}

Finally, 20 patients were enrolled in a study which compared the effects of a bakumondoto preparation in combination with conventional medication to conventional medication alone [15]. Bakumondoto, a TCM preparation, was delivered as 'TJ-29 powder', containing extracts of 6 herbs (ophiopogonis, pinelliae, zizyohi, licquorice, oryzae, and ginseng). The conventional medication consisted of a $\beta-2$ sympathomimetic agent, taken twice daily. An additional medication (dextromethorphan) was given if patients experienced severe cough symptoms.

The study results showed that both treatment groups needed the additional medication due to severe cough symptoms, but the effect of bakumondoto on the intensity of the patients' coughs was significantly stronger on days 4 and 5 of intake. No serious adverse events were reported in this study. Further quantitative analysis was inappropriate, given that this was the only study assessing the effect of bakumondoto and that it contained too little information to assess its quality. Due to lacking data in study randomization, blinding, and compliance, this study was labeled with a high risk of bias

\section{Discussion}

Many herbal preparations are available for purchase over-thecounter (e.g. Echinilin ${ }^{\mathrm{TM}}$, Prospan ${ }^{\circledR}$, Vicks ${ }^{\circledR}$ VapoRub ${ }^{\mathrm{TM}}$ ), having been tested as safe and distributed under German pharmaceutical law.

\section{Effects in Detail}

All 6 studies evaluating the effect of A. paniculata on cough found positive results. All of these high-quality studies, along with the results of the meta-analyses conducted, revealed strong evidence that A. paniculata reduces frequency and severity of patients' cough symptoms.

Several studies with a low risk of bias showed that $P$. sidoides reduces duration and severity of patients' cough symptoms without serious adverse effects, although the results of additional quantitative analysis were not distinct. $P$. sidoides showed moderate evidence of benefit in adults, yet positive effects in children were less clear.

Most of the reviewed studies found that ivy/primrose/thymebased preparations were superior to placebo in reducing cough symptoms $[34,35,37]$. This meta-analysis supports these findings, showing strong evidence for the preparation's benefits. All of these studies were of high quality, with a low risk of bias. These findings are in line with the European Guideline Committee's recommendations for the administration of ivy/primrose/thyme-based preparations improving secretolysis as an effective mucolyticum.

Three studies each with a low risk of bias investigated the effects of essential oils on patients' cough symptoms [38-40]. All studies found that essential oils improved the severity and frequency of these symptoms. The study by Matthys [38] also showed good clinical effects from essential oils, but found them not superior to conventional medication. Additionally, use of essential oil showed many adverse events.

None of the reviewed studies found that the Echinacea-based preparations alleviated patients' cough symptoms, regardless of their varied dosages and intake durations. All of these studies were of high quality and a low risk of bias. Despite these findings, some patients reported that although Echinacea had failed to improve their cough, it had reduced other cold-related symptoms [16, 42, $43,45]$. In some cases, patients noted it had also shortened their illness [42, 45]. Quantitative analyses by Bräuning and Dorn [16] and Schulten et al. [45] tend to support these qualitative findings.

Finally, the study results on the effects of bakumondoto were positive, yet of questionable validity, given this study's high risk of bias due to a high dropout rate and lack of information on study blinding and randomization procedures. It is also doubtful if the findings from such a small study can be generalized.

\section{Comparison with Past Reviews}

A review by Ziment [48] compared the effects of various phytotherapeutics on cough symptoms considering the extent to which these effects had been investigated adequately at the time of the review. He concluded that adequate proof existed for the benefit of pungent spices and menthol only; evidence for other common herbal agents, including peppermint, thyme, ivy and primrose, was missing.

\section{External and Internal Validity}

All 34 studies reviewed were double-blind RCTs, conducted with patients aged from 1 to 86 years. Patients' baseline characteristics were comparable in 31 of these studies; the remaining 2 studies included no data to allow such a comparison. The patient data is likely to represent a general population. All of the reviewed studies, except 4 , were of high quality, with a low risk of methodologi- 
cal bias. The randomization and blinding procedures were generally appropriate, although only half of the reviewed trials used an intention-to-treat analysis. The range of the evaluated populations and the methodological quality of the initial research allow these findings to be generalized to a population at large.

\section{Strengths and Limitations}

This is the first meta-analysis of phytotherapeutics as a remedy for cough symptoms. The overall risk of methodological bias in the reviewed studies was low, with 29 of 33 included trials having low risk of bias. The main challenge was to select the conditions to be included in the review, since cough symptoms have many complex causes. Another limitation was language. For example, there are many studies on TCM remedies for cough symptoms that were not considered as they are written in Chinese. Not every intervention was part of the meta-analysis, since for some remedies the number of trials was not sufficient (e.g. on the use of essential oils and bakumondoto). In some interventions, there was also a significant heterogeneity of results (e.g. A. paniculata and Echinacea). The designs of the reviewed Echinacea trials also proved highly diverse, both in terms of the dosages and the ingestion periods, making the comparison of results across these trials challenging. Finally, some trials were supported by the remedy manufacturers. For example, Bronchipret ${ }^{\circledR}$ was supplied by manufacturer Bionorica AG, Neumarkt, Germany [35] and EchinaFresh ${ }^{\circledR}$ by Enzymatic Therapy, Green Bay, WI, USA. [46]. Whilst all authors stated that such sponsorship had not affected their data acquisition or results, potential bias from this source bears consideration.

\section{Implications for Clinical Practice}

A number of high-quality studies show that herbal preparations containing A. paniculata, ivy/primrose/thyme, essential oils, and $P$. sidoides improve the severity and frequency of patients' cough symptoms, with few mild adverse effects.

With regard to A. paniculata,_5 days intake of a proprietary preparation such as KalmCold ${ }^{\circledR}$ or KanJang ${ }^{\circledR}$ appears adequate to alleviate patients' cough symptoms. More specifically, the evaluation of $P$. sidoides intake over 7 days with a dosage of $90 \mathrm{mg}$ shows that this treatment is sufficient to attain significant relief from cough symptoms in adults. Pediatric dosages require appropriate adjustment.

In case of productive cough, ivy/primrose/thyme-based preparations and essential oils can be recommended as secretolysis is enhanced and facility of coughing up mucus is improved; additionally, sleep disturbance is reduced.

Intake of ivy/primrose/thyme-based preparations, such as Mintetten, over ca. 10 days, also seems to improve patients' cough symptoms at a low dosage of $30 \mathrm{mg}$ [37]. Information on the effects of a higher dose is missing, however.

Concerning essential oils, dosages of $1,2 \mathrm{~g}$ myrtol per day seem to be adequate for adults to alleviate patients' cough. Effects of oral medication were reached in about one week. Ointments, such as Vicks VapoRub, alleviated childrens' cough immediately, making it a useful supplement to other interventions.
Unfortunately it seems that essential oils bear potential to evoke adverse events (in most cases mild adverse events occurred which needed no further treatment).

As a result of these findings, the above-mentioned preparations may be strongly recommendable, alongside conventional medications, to adults who experience acute cough symptoms. Further research comparing phytotherapeutics with conventional cough remedies is needed before recommendations can be made on the use of herbal preparations alone.

With regard to the use of Echinacea, the results were more equivocal. Although this preparation proved beneficial from a quantitative perspective, on a qualitative level most trials showed no significant effects of Echinacea on patients' cough symptoms. Yet, Echinacea did appear to significantly improve patients' other cold-related symptoms and to shorten the duration of their illnesses $[16,42,43,45]$. Significant heterogeneity in the study designs, methods, and results make recommendations in this area challenging. Echinacea was tested in varied compositions, in different administration forms (solutions, teas, and solids), and different durations of intake, but revealed no clear benefit on patients' cough symptoms.

Finally, there was only one study assessing the effects of bakumondoto on cough symptoms. Although this study was of high quality and showed good outcomes, its results cannot be appropriately generalized to a broader population. In addition, this study tested bakumondoto alongside a $\beta-2$ sympathomimetic agent and dextromethorphan, making it difficult to determine the active components. Against the background of these findings, neither Echinacea nor bakumondoto can be recommended as adequate cough remedies.

\section{Implications for Further Research}

Further overviews of phytotherapeutics against cough symptoms, with studies in Chinese and English in the field of TCM, are needed to extend knowledge about their use - not least in view of the potential to identify additional phytotherapeutic agents to review.

Further high-quality trials on Echinacea for cough are needed to reduce the current heterogeneity of findings in this area, thereby facilitating the assessment of effects on the basis of comparable data.

Further research is needed to compare complementary/alternative approaches with conventional pharmaceuticals for cough symptoms in order to evaluate the potential of herbal remedies as supplement or even alternative to conventional treatment.

\section{Conclusion}

This review found strong evidence that A. paniculata and ivy/ primrose/thyme-based preparations were significantly superior to placebo in alleviating the frequency and severity of patients' cough symptoms. P. sidoides and essential oils showed moderate results in this respect. Only few minor adverse effects were reported, suggest- 
ing that these phytotherapeutics may be recommended as an adjunct to conventional medicine. Additional research, including other herbal treatments, is needed in this area.

\section{Acknowledgments}

This review was supported by a grant from the Rut and Klaus Bahlsen Foundation, Hanover, Germany. The funding source had no influence on the design or conduct of the review; the collection, management, analysis or interpretation of the data; or on the preparation, review or approval of the manuscript.

\section{Disclosure Statement}

The authors declare that they have no competing interests.

\section{Supplemental Material}

To access the supplemental material please refer to www.karger.com/ doi/10.1159/000442111.

Appendix I. Characteristics of the included studies

Appendix II. Risk of bias of the included studies

Appendix III. Excluded studies

\section{References}

1 Morice AH: Epidemiology of cough. Pulm Pharmacol Ther 2002;15:253-259.

2 Barbee RA: A longitudinal study of respiratory symptoms in a community population sample. Correlations with smoking, allergen skin-test reactivity, and serum IgE. Chest 1991;99:20-26.

3 McGarvey LP, Heaney LG, Lawson JT: Evaluation and outcome of patients with chronic non-productive cough using a comprehensive diagnostic protocol. Thorax 1998;53:738-743.

4 Rubin BK: Mucolytics, expectorants, and mucokinetic medications. Respir Care 2007;52:859-865.

5 Schroeder K: Systematic review of randomised controlled trials of over the counter cough medicines for acute cough in adults. BMJ 2002;324:329-331.

6 Brendler T, van Wyk BE: A historical, scientific and commercial perspective on the medicinal use of Pelargonium sidoides (Geraniaceae). J Ethnopharmacol 2008;119:420-433.

7 Kindscher K: Ethnobotany of purple coneflower (Echinacea angustifolia, Asteraceae) and other Echinacea species. Econ Bot 1989;43:498-507.

8 Singh AK, Raghubanshi AS, Singh JS: Medical ethnobotany of the tribals of Sonaghati of Sonbhadra district, Uttar Pradesh, India. J Ethnopharmacol 2002;81: 31-41.

9 Kardos P, Berck H, Fuchs KH: Guidelines of German Respiratory Society for diagnosis and treatment of adults suffering from acute or chronic cough. Pneumologie 2010;64:336-373.

$\checkmark 10$ Furlan AD, Pennick V, Bombardier C: 2009 updated method guidelines for systematic reviews in the Cochrane Back Review Group. Spine (Phila Pa 1976) 2009;34:1929-1941.

11 Cohen J: Statistical Power Analysis for the Behavioral Sciences. Technometrics 1989;31:499-500.

12 van Tulder M, Furlan A, Bombardier C: Updated method guidelines for systematic reviews in the Cochrane Collaboration Back Review Group. Spine 2003;28:1290-1299.

13 Higgins JP, Thompson SG, Deeks JJ, Altman DG: Measuring inconsistency in meta-analyses. BMJ 2003; 327:557-560.

14 Stafunsky M, Manteuffel GE: Therapie der akuten Tracheobronchitis mit ätherischen Ölen und mit Soleinhalation - ein Doppelblindversuch. Z Phytother 1989; 10:130-134.

15 Irifune K, Hamada H, Ito R: Antitussive effect of bakumondoto a fixed kampo medicine (six herbal components) for treatment of post-infectious prolonged cough: controlled clinical pilot study with 19 patients. Phytomedicine 2011;18:630-633.
16 Bräuning B, Dorn M: Echinaceae purpureae radix: zur Stärkung der körpereigenen Abwehr bei grippalen Infekten. Z Phytother 1992;13:7-13.

17 Matthys H, Lizogub VG, Malek FA: Efficacy and tolerability of EPs 7630 tablets in patients with acute bronchitis: a randomised, double-blind, placebo-controlled dose-finding study with a herbal drug preparation from Pelargonium sidoides. Curr Med Res Opin 2010; 26:1413-1422.

18 Saxena RC, Singh R, Kumar P: A randomized double blind placebo controlled clinical evaluation of extract of Andrographis paniculata (KalmCold) in patients with uncomplicated upper respiratory tract infection. Phytomedicine 2010;17:178-185.

19 Caceres DD, Hancke JL, Burgos RA: Use of visual analogue scale measurements (VAS) to assess the effectiveness of standardized Andrographis paniculata extract SHA-10 in reducing the symptoms of common cold. A randomized double blind-placebo study. Phytomedicine 1999;6:217-223.

20 Melchior J, Spasov AA, Ostrovskij OV: Double-blind, placebo-controlled pilot and phase III study of activity of standardized Andrographis paniculata herbal nees extract fixed combination (Kan jang) in the treatment of uncomplicated upper-respiratory tract infection. Phytomedicine 2000;7:341-350.

21 Narimanian M, Badalyan M, Panosyan: Randomized trial of a fixed combination (KanJang) of herbal extracts containing Adhatoda vasica, Echinacea purpurea and Eleutherococcus senticosus in patients with upper respiratory tract infections. Phytomedicine 2005; 12: 539-547.

22 Thom E: A controlled clinical study of Kanjang mixture in the treatment of uncomplicated upper respiratory tract infections. Phytother Res 1998;11:207-2010.

23 Matthys H, Lizogub VG, Funk P: Pelargonium sidoides in acute bronchitis - health-related quality of life and patient-reported outcome in adults receiving EPs 7630 treatment (in German). Wien Med Wochenschr 2010; 160:564-570.

24 Matthys H, Eisebitt R, Seith B: Efficacy and safety of an extract of Pelargonium sidoides (EPs 7630) in adults with acute bronchitis. A randomised, double-blind, placebo-controlled trial. Phytomedicine 2003; 10(suppl 4):7-17.

25 Matthys H, Funk P: EPs 7630 improves acute bronchitic symptoms and shortens time to remission. Results of a randomised, double-blind, placebo-controlled, multicentre trial. Planta Med 2008;74:686-692.

26 Matthys H, Heger M: Treatment of acute bronchitis with a liquid herbal drug preparation from Pelargonium sidoides (EPs 7630): a randomised, double-blind, placebo-controlled, multicentre study. Curr Med Res Opin 2007;23:323-331.
27 Chuchalin AG, Berman B, Lehmacher W: Treatment of acute bronchitis in adults with a Pelargonium sidoides preparation (EPs 7630): a randomized, double-blind, placebo-controlled trial. Explore (NY) 2005; 1:437-445.

28 Lizogub VG, Riley DS, Heger M: Efficacy of a Pelargonium sidoides preparation in patients with the common cold: a randomized, double blind, placebo-controlled clinical trial. Explore (NY) 2007;3:573-584

29 Kamin W, Maydannik VG, Malek FA: Efficacy and tolerability of EPs 7630 in patients (aged 6-18 years old) with acute bronchitis. Acta Paediatr 2010;99:537-543.

30 Kamin W, Maydannik V, Malek FA, Kieser M: Efficacy and tolerability of EPs 7630 in children and adolescents with acute bronchitis - a randomized, doubleblind, placebo-controlled multicenter trial with a herbal drug preparation from Pelargonium sidoides roots. Int J Clin Pharmacol Ther 2010;48:184-191.

-31 Kamin W, Ilyenko LI, Malek FA: Treatment of acute bronchitis with EPs 7630: randomized, controlled trial in children and adolescents. Pediatr Int 2012;54:219226

32 Blochin B, Haidvogl M: Umckaloabo im Vergleich zu Acetylcystein bei Kindern mit akuter Bronchitis. Prospektive, randomisierte, kontrollierte, offene Studie zur Wirksamkeit und Verträglichkeit. Der Kassenarzt 1999;49:46-50.

33 Timmer A, Günther J, Rücker G: Pelargonium sidoides extract for acute respiratory tract infections. Cochrane Database Syst Rev 2008;3:CD006323.

34 Kemmerich B: Evaluation of efficacy and tolerability of a fixed combination of dry extracts of thyme herb and primrose root in adults suffering from acute bronchitis with productive cough. A prospective, double-blind, placebo-controlled multicentre clinical trial. Arzneimittelforschung 2007;57:607-615.

35 Kemmerich B, Eberhardt R, Stammer H: Efficacy and tolerability of a fluid extract combination of thyme herb and ivy leaves and matched placebo in adults suffering from acute bronchitis with productive cough. A prospective, double-blind, placebo-controlled clinical trial. Arzneimittelforschung 2006;56:652-660.

36 Cwientzek U, Ottillinger B, Arenberger P: Acute bronchitis therapy with ivy leaves extracts in a two-arm study. A double-blind, randomised study vs. an other ivy leaves extract. Phytomedicine 2011;18:1105-1109.

37 Kurth W: Gesicherte therapeutische Wirksamkeit des traditionellen Antitussivums Mintetten im Doppelblindversuch. Med Welt 1978;29:1906-1909.

38 Matthys H, de Mey C, Carls C: Efficacy and tolerability of myrtol standardized in acute bronchitis. A multicentre, randomised, double-blind, placebo-controlled parallel group clinical trial vs. cefuroxime and ambroxol. Arzneimittelforschung 2000;50:700-711. 
39 Paul IM, Beiler JS, King TS: Vapor Rub, Petrolatum, and no treatment for children with nocturnal cough and cold symptoms. Pediatrics 2010;126:1092-1099.

40 Gillissen A, Wittig T, Ehmen M: A multi-centre, randomised, double-blind, placebo-controlled clinical trial on the efficacy and tolerability of GeloMyrtol ${ }^{\circledR}$ forte in acute bronchitis. Drug Res (Stuttg) 2013;63 19-27.

41 Barrett BP, Brown RL, Locken K: Treatment of the common cold with unrefined Echinacea. A randomized, double-blind, placebo-controlled trial. Annals Intern Med 2002;137:939-946.
42 Cohen HA, Varsano I, Kahan E, Sarrell EM, Uziel Y: Effectiveness of an herbal preparation containing Echinacea, propolis, and vitamin $\mathrm{C}$ in preventing respiratory tract infections in children: a randomized, doubleblind, placebo-controlled, multicenter study. Arch Pediatr Adolesc Med 2004;158:217-221.

43 Goel V, Lovlin R, Barton R: Efficacy of a standardized Echinacea preparation (Echinilin) for the treatment of the common cold: a randomized, double-blind, placebo-controlled trial. J Clin Pharm Ther 2004;29:75-83. 44 O'Neil J, Hughes S, Lourie A: Effects of Echinacea on the frequency of upper respiratory tract symptoms: a randomized, double-blind, placebo-controlled trial. Ann Allergy Asthma Immunol 2008;100:384-388.
45 Schulten B, Bulitta M, Ballering-Brühl B: Efficacy of Echinacea purpurea in patients with a common cold. A placebo-controlled, randomised, double-blind clinical trial. Arzneimittelforschung 2001;51:563-568.

6 Yale SH, Liu K: Echinacea purpurea therapy for the treatment of the common cold: a randomized, doubleblind, placebo-controlled clinical trial. Arch Intern Med 2004;164:1237-1241

47 Sperber SJ, Shah LP, Gilbert RD: Echinacea purpurea for prevention of experimental rhinovirus colds. Clinical Infect Dis 2004;38:1367-1371.

48 Ziment I: Herbal antitussives. Pulm Pharmacol Ther 2002;15:327-333. 